\title{
FACES DA MORTE NA POESIA DE JORGE DE SENA
}

Rodrigo Corrēa Martins Machado*

Resumo: Este trabalho tem como principal objetivo investigar e analisar algumas das distintas representações da morte presentes na poética seniana. Para tanto, detive-me mais especificamente em três notáveis faces da morte com as quais me deparei e que busquei me aprofundar: a morte como aniquilamento do ser; como trânsito deste mundo para um além inescrutável; e, por fim, como término do possível de si. Em cada uma delas há um sujeito poético angustiado, seja pela não aceitação de sua finitude, seja pelo desejo de a escrita poética ser uma espécie de continuidade de si, seja pela constatação de que a própria vida pode tornar-se um espaço tumular.

Palavras-chave: Jorge de Sena. Morte. Poesia e filosofia.

Eu creio que isto é morte. Durará ou muito ou pouco tempo até o fim.

Mas é a morte me inundando fria.

Ouvir como no longe que se fala,

Sentir os risos como casquinadas

Vazias de sentido. Ler com tédio

Mesmo o dito melhor de qualquer tempo.

E nada desejar senão silêncio

e a luz como se o espaço fora opaco.

[...]

Sentir uma agonia descendida

da mente às vísceras que volta à mente

levando algumas dores e borborigmas

de uma presença física e pesada 
com o que pensar se aflige de arrastar

um corpo desistido e a desfazer-se.

[...] (SENA, 2015, p. 758-759).

7

nicio este ensaio com os senianos versos de "Os poetas envelhecem", os quais, a meu ver, são representativos no que diz respeito ao tema da morte. Nesse poema, utilizado como epígrafe, já é possivel constatar uma sentida angústia acerca do fim da vida em que nos deparamos com "um corpo desistido e a desfazer-se". Foi com base na leitura dele que iniciei o questionamento em torno das figurações da morte que poderia encontrar na produção poética seniana. Em uma pesquisa mais ampla entre os poemas contidos em Poesia 1 (2014) e Poesia 2 (2015), notei de maneira mais detida que vários são os poemas de Sena em que o extinguir da vida mostra algumas de suas múltiplas faces. Trata-se de poemas que, de diferentes modos, representam angústias perante essa inevitável etapa da vida humana. Sendo assim, me proponho neste trabalho a analisar algumas representações da morte encontradas na poesia de Jorge de Sena.

A partir das minhas leituras, acredito ser possivel afirmar que há uma ética da morte na poesia de Jorge de Sena, uma vez que os sentimentos que suscitados pelo cessar da vida possibilitam ao sujeito poético construir caminhos distintos em relação ao ato de morrer, colocando a si próprio (e a humanidade) em questão. Dessa forma, Sena faz de seus poemas especulações existenciais e filosóficas sobre o morrer. Como é possivel depreender da leitura do poema epígrafe deste trabalho, em que o sujeito sente a agonia da morte inundando-o, a poesia seniana tem em si uma violação de interditos, contestação, ela é escrita de tensões entre mundo e a própria palavra, entre experiências interiores e a realidade que cerca o poeta. Como o autor de Metamorfoses afirma em seu prefácio à Poesia I, "Como um processo testemunhal sempre entendi a poesia, cuja melhor arte consistirá em dar expressão ao que o mundo (o dentro e o fora) nos vai revelando [...]" (SENA, 1961, p. 11-12).

De acordo com Philippe Ariès, em História da morte no Ocidente (2012), até o século XIX, a morte era considerada uma ruptura, ao mesmo tempo atraente e terrivel, uma convivência entre Eros e Thânatos. Entretanto, a partir de então, há diante da morte uma atitude de medo que faz que se cesse de representá-la. Diz o historiador: "Esse medo da morte manifestou-se, em seguida, pela repugnância, primeiro, em representar e, depois, em imaginar o morto e seu cadáver" (ARIĖS, 2012, p. 151). Isto significa que retratar a morte, questionar a sua naturalidade, refletir sobre ela é um ato de violação deste grande interdito na cultura ocidental da qual fazemos parte. Ao fazer isso em sua escrita poética, Jorge de Sena cria poemas violadores desse interdito e que são palcos nos quais estão em cena especulações-dramatizações advindas da morte.

Enquanto elemento silenciado-interdito, a morte é vertiginosa e fascinante, aparecendo nas mais antigas representações humanas de variadas maneiras, com diversas faces. Nas palavras de Georges Bataille (2014, p. 29), o ser humano não possuiria nenhuma chance de emitir alguma luz antes de dominar o que o apavora. Para tanto, é preciso encarar de frente o próprio elemento de pavor. Trata-se de uma ótica dual, em que pavor e sedução se misturam de forma a se perderem um no outro. 
Na poesia de Jorge de Sena é possivel vislumbrar várias atitudes diante da morte, como bem aponta Ana Maria Gottardi (2002). No entanto, para a feitura deste trabalho, três ${ }^{1}$ são as que gostaria de me deter: a morte como aniquilamento do ser; como trânsito deste mundo para um além inescrutável; e, por fim, como término do possível de si. Na primeira, nitidamente nota-se uma atitude de recusa e resistência, por ser antinatural; na segunda, a resistência parte de outra nuança: da escrita enquanto continuidade da voz do sujeito; e, na última, o sujeito tem a morte como fim de sua existência.

Como exemplo da primeira atitude diante da morte apontada anteriormente, gostaria de destacar o célebre poema "A morte, o espaço e a eternidade", parte da obra Metamorfoses (1963). Este poema é um claro exemplo de negação da morte, como nos diz o próprio sujeito poético:

De morte natural nunca ninguém morreu.

Não foi para morrer que nós nascemos, não foi só para a morte que dos tempos chega até nós esse murmúrio cavo, inconsolado, uivante, estertorado, desde que anfibios viemos a uma praia e quadrumanos nos erguemos. Não.

Não foi para morrermos que falámos, que descobrimos a ternura e o fogo, e a pintura, a escrita, a doce música. Não foi para morrer que nós sonhámos ser imortais, ter alma, reviver, ou que sonhámos deuses que por nós fossem mais imortais que sonharíamos. Não foi. Quando aceitamos como natural, dentro da ordem das coisas ou dos anjos, o inominável fim da nossa carne; quando ante ele nos curvamos como se ele fora inescapável fome de infinito; quando vontade o imaginamos de outros deuses que são rostos de um só; quando que a dor é um erro humano a que na dor nos damos porque de nós se perde algo nos outros, vamos traindo esta ascensão, esta vitória, isto que é ser-se humano, passo a passo, mais.

A morte é natural na natureza. Mas nós somos o que nega a natureza. Somos esse negar da espécie, esse negar do que nos liga ainda ao Sol, à terra, às águas. Para emergir nascemos. Contra tudo e além de quanto seja o ser-se sempre o mesmo que nasce e morre, nasce e morre, acaba como uma espécie extinta de outras eras. [...] (SENA, 2014, p. 355-356).

As duas primeiras representações referidas são apontadas, mas não desenvolvidas por Ana Maria Gottardi (2002). A terceira é apontada por mim. 
No poema, deparamos com uma explícita negação da morte: "A morte é natural na natureza. Mas/nós somos o que nega a natureza. Somos/esse negar da espécie, esse negar do que nos liga ainda ao Sol, às terras, às aguas" (SENA, 2014, p. 355-356). E isso pode relacionar-se ao fato de o ser humano, racional, diante dela - ou de sua possibilidade real - ser lançado em uma animalidade que já perdera há muitos séculos, acabando por esquecer que não é imortal. Para Bataille (2016, p. 106), “A morte é, num sentido, vulgar, inevitável, mas, num sentido profundo inacessivel. O animal a ignora, embora ela lance o homem de volta à animalidade. O homem ideal que encarna a razão permanece-lhe estranho".

O sujeito poético seniano assinala exatamente o caráter inumano, horrendo da morte: "Não foi para morrermos que falámos, /que descobrimos a ternura e o fogo,/e a pintura, a escrita, a doce música" (SENA, 2014, p. 355-356). Ela, tantas vezes negada, esquecida, conscientemente escondida nos mais recônditos espaços, exaspera no homem a angústia e o horror. Ela "não é menos o desejo desvairado de ser eu do que aquele de não ser mais nada" (BATAILLE, 2016, p. 106).

Diante do horror da morte, o eu poético se insurge. Ele resiste. Mesmo sabendo que vai morrer em algum momento, ele a recusa, apontando-a como irracional, ou seja, inumana. Em várias passagens, essa recusa se faz poema: "Tudo se fez para escapar-lhe, tudo/se imaginou para iludi-la, tudo/até coragem, desapego, amor/para que a morte fosse natural [...] Não há limites para a Vida" (SENA, 2014, p. 355-356).

A vida, nesse poema, é nada menos que negação da morte. É sua condenação, exclusão. Se, de acordo com Philippe Ariès, até o início do século XIX, a convivência com a finitude humana era relativamente pacífica, a partir de então o negar a morte tornou-se cada vez mais intenso. O ser humano busca a eternidade em vida, explora outros espaços, órbitas, desbrava mundos e realidades só imaginados em utopias ficcionais - como bem representado pela figura que acompanha o poema, imagem do Sputnik I, o primeiro satélite artificial lançado da Terra, em 1957. Apesar de todos os avanços científicos e tecnológicos, ainda não se descobriu nenhuma fórmula da vida, ou fonte da eterna juventude. Indignado, o sujeito poético profere:

É uma injustiça a morte. É cobardia que alguém a aceite resignadamente. O estado natural é complacência eterna, é uma traição ao medo por que somos, àquilo que nos cabe: ser o espírito sempre mais vasto do Universo infindo. [...] (SENA, 2014, p. 355-356).

Ana Maria Gottardi (2002, p. 161) revela que, em Sena, a resistência à morte revela-se nas asserções negativas, na recusa, na reafirmação da recusa, na valorização do medo da morte e valorização da vida, "até a sua identificação com o infinito, ou Deus, mas um Deus produto do espírito humano”. Como é possivel assinalar, em "A morte, o espaço e a eternidade", Deus é convidado a encenar:

Não foi para morrer que nós sonhamos

ser imortais, ter alma, reviver

ou que sonhamos deuses que por nós

fossem mais imortais que sonharíamos. 
[...]

E Deus não quer que nós, nenhum de nós,

nenhum aceite nada. Ele espera

como um juiz na meta da corrida,

Torcendo as mãos de desespero e angústia,

porque não pode fazer nada e vê

que os corredores desistem, se acomodam,

ou vão tombar exaustos no caminho.

De nós se acresce ele mesmo que será

o espírito que formos, o saber e a força.

[...] (SENA, 2014, p. 355-356).

A encenação que traz à luz a presença divina nada mais é que vontade de humano, racionalização, é um verdadeiro convite ao desafio, de maneira tal que se assemelha a um novo caminho para as indias modernas em que o desejo maior é de ultrapassá-lo, de negá-lo, em que a ressurreição humana "é morte desse Deus que nos espera" (SENA, 2014, p. 355-356).

A morte em Sena aparece também como trânsito deste para outro mundo, circulação entre espaços e tempos que, mais que significar finitude existencial, pode também deixar resquícios de continuidade por meio da cultura e do próprio poema enquanto sua manifestação. Como exemplo desta outra face da morte, selecionei o poema "Sacrificio da imortalidade", publicado em Tempo de Coroa da Terra, 1942-1944:

A minha voz quando estiver tão longe, que apenas eruditos ma percebam, no que, do tempo, eu não levei comigo, já não dirá desilusões ou sonhos, quantas esperanças dei não crendo nelas, para que as vissem quem não via o mundo, ou visse o mundo alguém, mesmo sem elas - será como um silêncio do passado, onde o futuro se advinha extremo, e não sabemos qual, se será vosso, se outro será, de que nasceu conosco o erro de o julgar, como se fora alheia a liberdade ao próprio tempo...

E só no tempo em vão me perderei.

[...] (SENA, 2015, p. 501).

Este poema tem em si não só o performativo de um sujeito que se escreve na própria morte, como também um novo olhar diante dela, uma visão de continuidade. Por mais que ele sacrifique a sua imortalidade carnal, abra mão de sua existência no mundo, a sua permanência lhe será assegurada por meio da escrita, pela presença da sua voz. A morte neste poema não possui sentido de fim, uma vez que, mesmo sendo ouvida apenas por eruditos, se fará presente. Para Ernest Becker (1995), em A negação da morte, o desejo de continuação do nosso ser na eternidade, através de que modo se manifestar, atua para acalmar o ser humano, a fim de que ele não precise ter nenhuma angústia. 
No poema, a voz metafórica se torna, pois, vida, carne em que confluem o sangue e o desejo de falar, como bem aponta o poema "Efêmero", presente em Tempo de Perseguição, 1938-1942: "A carne que possuo é minha voz./É única, é suja... mas escorre/a baba, sangue, o suor e o mais que escorre/de um corpo humano sob e contra nós" (SENA, 2015, p. 399). Por meio da escrita, o sujeito materializa-se, dá formas e contornos às suas ideias e o poema, enquanto espaço erótico de tensões, passa a ser palco de desejo e de atrito voluptuoso entre aquele que fala e quem o lê.

O sujeito poético de "Sacrificio da imortalidade" se sabe enquanto ser que, temporalmente, sempre será de cultura, tendo o poema enquanto máxima representação de seus anseios, desejos e medos. Por esse motivo, a voz que depreende do peito-papel desse mesmo sujeito se recusa ao silêncio. Ela é vocalização de um movimento interior que ultrapassa esse ser no tempo e espaço, é som de passado com desejo de futuro: "Será mistério, escuridão, cansaço,/memória tênue de ansioso abraço,/em volta de um saber de coisa alguma [...]" (SENA, 2015, p. 501).

Esse eu poético se desnuda diante do leitor de modo a reconhecer que a sua voz no futuro não será retorno, justamente porque cada leitor que com ela travar contato escutará diferentes nuanças do som: "O que ficou/jamais dirá que tornarei a ser" (SENA, 2015, p. 501). Como bem destaca Octavio Paz (2012, p. 198), o poeta ao falar de fatos, experiências, sentimentos e pessoas, fala-nos do próprio ato de criar e nomear, levando o leitor a repetir e recriar o poema e, assim, "o leitor recria o instante e cria a si mesmo". Por isso, mesmo afastados anos ou séculos um do outro, na comunhão poética entre poema e leitor, o que há de ser lido é sempre outra coisa, e isso feito de distintas maneiras. Tendo a escrita enquanto permanência, a cada leitor que com ela travar contato o poema será modificado, indo ao encontro com o que diz Octavio Paz (2012, p. 198) em relação ao poema ser sempre uma obra inacabada, "sempre disposta a ser completada e vivida por um novo leitor". Tendo em consideração esse caráter do poema ser algo sempre em devir, é possível sublinhar que em "Sacrificio da imortalidade" a morte não é um ato banal, porque não é o fim.

A terceira e última face da morte que desejo apresentar neste trabalho aparece na poesia de Jorge de Sena como término do sujeito, finitude existencial, sem em nenhum momento apontar para desejo de continuidade, seja por meio da escrita, seja em direção e uma existência post mortem. Essa visão é muito bem representada pelo poema "Morte...", parte da seção de Poesia 2, intitulada Primeiro Tempo, 1936-1938:

\author{
Quando morrer \\ não verei o mundo apagar-se, \\ enegrecer, \\ à minha volta. \\ Morrerei de olhos fechados. \\ Mesmo quando morrer \\ já estarão mais do que fechados \\ porque os fechei há muito \\ ao espaço que rodeia \\ a minha presença material \\ de cada instante...
}




\begin{abstract}
Morrer para mim não será deixar de ver, nem de ouvir, nem de sentir qualquer coisa, porque os meus outros sentidos também descansam do cansaço de não terem encontrado o cansaço procurado...

Enfastiaram-se de monotonia... Queriam outros perfumes... outra gente... outros horizontes... e não tiveram nada, tiveram mal, ou tiveram para depois ficarem com menos do que tinham...
\end{abstract}

Na minha morte não há-de haver despedida dos sentidos. As despedidas já estão feitas.

A minha morte há-de ser só morte, uma simples morte de morrer... (SENA, 2015, p. 200-201).

O primeiro elemento que me salta aos olhos na leitura deste poema é o fato de a aniquilação, finitude do ser, não estar relacionada apenas ao momento específico da morte. Em vida, o sujeito já se mostra desprovido de desejos, de liberdade, entregue a indignidade. Ao considerar este aspecto, é possivel evocar o que diz Ernest Becker (1995) em relação às diferentes imagens que o ser humano pode traçar e escolher para si no tocante à morte; para ele, há aquela em que o indivíduo, atirado aos seus próprios parcos poderes, parece muito pouco livre para deslocar-se e muitíssimo desprovido de dignidade. $\mathrm{E}$ isso vai ao encontro do sujeito poético seniano que, de maneira um tanto quanto melancólica, vai revelando que a própria vida que vive já se assemelha a um apagamento: "Mesmo quando morrer/já estarão mais do que fechados/porque os fechei há muito/ ao espaço que rodeia/a minha presença material/de cada instante [...]" (SENA, 2015, p. 200-201). Nesse caso, a vida tornou-se lápide, espaço sepulcral em que o sujeito poético apenas respira à espera de "uma simples morte de morrer" (SENA, 2015, p. 200-201).

De alguma forma, esse eu poético tornado em pedra, em ser que performativamente se diz em estado vegetativo, vive em uma espécie de exílio auto-imposto causado pelo enfastiamento de uma vida monótona. Trata-se de um ser tomado por uma profunda melancolia diante de uma vida que poderia ter sido outra e à qual foram negados "[...] outros perfumes.../outra gente.../outros horizontes..." (SENA, 2015, p. 200-201). Um sujeito que diz não ter tido nada ou, quando teve algo que desejou, "[...] tiveram para depois ficarem/com menos que tinham..." (SENA, 2015, p. 200-201). 
O leitor deste poema se vê diante de uma morte como continuidade de um apagamento iniciado em vida, perante um poema tumular, em que o sujeito poético se fecha e anuncia que "As despedidas já estão feitas" (SENA, 2015, p. 200-201), mesmo antes de a vida findar. Mais que desejo de desaparecimento, o poema se faz enquanto constatação de um alguém que não verá as luzes do mundo apagarem-se, por estar nele de olhos fechados. Por isso, essa escrita não se assemelha a uma voz de um alguém que deseja permanência e, sim, como testemunho de uma vida vivida em desencanto, desespero e abandono.

\section{CONSIDERAÇões FINAIS}

O título deste trabalho aponta a existência na poética seniana de mais de uma face da morte. Cada uma delas aborda três maneiras distintas de Jorge de Sena abordar este tema que, para Philippe Ariès, tornou-se um interdito nas sociedades ocidentais a partir do século XIX. O historiador francês destaca que do século XX em diante criou-se mecanismos a fim de que, ao não ser vista, a morte não fosse falada, como exemplificado pelo próprio ato da cremação. Ou seja, falar e expor as angústias diante da morte é algo que viola o silêncio imposto nas sociedades, que coloca o ser humano frente a frente com o seu maior medo: o de extinguir.

Nem mesmo após tantos avanços técnico-científicos, como a descoberta de novas galáxias e planetas, a ida do homem à lua e a criação de inteligência artificial, o ser humano foi capaz de driblar seu caráter finito. E os poemas senianos analisados neste trabalho apontam três modos distintos de lidar com a angústia causada pela possibilidade da morte - apenas possibilidade, uma vez que se trata de poemas em que o sujeito poético performatiza o morrer para com ele lutar ou acatá-lo de maneiras distintas.

As três mortes apresentadas possivelmente não são as únicas a aparecerem em um autor com tão avultante produção poética. No entanto, elas nos possibilitam afirmar que, com base nas próprias experiências singulares perante a morte, Sena é capaz de criar poemas de mais extrema especulação filosófico-existencial. Nesse caso, a escrita poética torna-se palco de encenação de experiências que são (e se fazem) o próprio poema, uma vez que é na escrita poemática que "O desejo de conhecer é aî incessantemente misturado ao desejo contrário, o de tirar de cada coisa a parte de desconhecido que ela contém" (BATAILLE, 2016, p. 107). Logo, as especulações que o autor faz em relação ao tema da morte colocam em questão a si mesmo e, consigo, toda a humanidade.

\section{Faces of Death in Jorge de Sena's POETRY}

Abstract: The main objective of this work is to investigate and analyze some of the different representations of death present in seniana poetics. For this, I focused more specifically on three main faces of death that I came across and which I sought to deepen: death as the annihilation of being; as transit from this world into an inscrutable beyond; and, finally, as the end of the possible of itself. In each of them there is an anguished poetic subject, either by the nonacceptance of its finitude, or by the desire of poetic writing to be a kind of continuity of itself, either by the realization that life itself can become a tomb space.

Keywords: Jorge de Sena. Death. Poetry and philosophy. 


\section{REFERÊNCIAS}

ARIĖS, P. História da morte no Ocidente: da Idade Média aos nossos dias. Tradução Priscila Viana de Siqueira. Rio de Janeiro: Nova Fronteira, 2012.

BATAILlE, G. O erotismo. Tradução Fernando Scheibe. Belo Horizonte: Autêntica, 2014.

BATAILlE, G. A experiência interior: seguida de método de meditação e Postscriptum 1953. Tradução Fernando Scheibe. Belo Horizonte: Autêntica, 2016.

BECKER, E. A negação da morte. Tradução Luiz Carlos do Nascimento Sila. Rio de Janeiro: Record, 1995.

GOTTARDI, A. M. Jorge de Sena: uma leitura da tradição. São Paulo: Arte \& Ciência, 2002.

PAZ, O. O arco e a lira. Tradução Ari Roitman e Paulina Watch. São Paulo: Cosac Naify, 2012.

SENA, J. Prefácio. In: SENA, J. Poesia I. Lisboa: Morais Editora, 1961.

SENA, J. Poesia 1 (obras completas). Edição e coordenação Jorge Fazenda Lourenço. Lisboa: Guimarães Editores, 2014.

SENA, J. Poesia 2 (obras completas). Edição e coordenação Jorge Fazenda Lourenço. Lisboa: Guimarães Editores, 2015.

Recebido em 25 de março de 2018. Aprovado em 18 de outubro de 2018. 